\title{
PREVENTION OF TUBERCULOSIS AT THE PRE-SCHOOL AGE-PERIOD.
}

\author{
By S. LYLE CUMMINS, C.B., C.M.G., M.D., \\ David Davies Professor of Tuberculosis, Welsh National School of Medicine, Cardiff.
}

WHEN we consider the question of the prevention of childhood tuberculosis, we are led to realize that there are two main lines of action open to us as follows :-

(I) The protection of the child from infection.

(2) The attempt to prevent "larval" tuberculosis from passing on into the generalized stage.

The first implies measures to control the occurrence of infection, the second measures to improve the environment of the already infected but as yet only potentially tuberculous child.

In considering the protection of the child from infection we have to direct our efforts, on the one hand, against the risk of milk from infected cows and, on the other, to devising measures against contamination with human tuberculosis.

As to the prevention of bovine infection, so often the cause of spinal disease, hipjoint disease, and the many forms of crippling and disfigurement which we associate with the surgical tuberculosis of childhood, this important side of the question can only be dealt with through the better control of milk supplies, and I propose to say no more about it here as the subject is now receiving close attention by the proper authorities.

When we turn, however, to the problem of the prevention of "human" infections, even a cursory examination of the facts suffices to convince us of the complexity of the problem.

Seeing that practically one hundred per cent. of clinically non-tuberculous adults in these islands react to tuberculin, it is quite evident that our efforts have, so far, failed to prevent infection, nor are they very likely to be more successful in the future.

It must be conceded that, from one source or another, everybody sooner or later gets at least so much tuberculosis as is necessary to make him tuberculin-sensitive.

To make our efforts against infection practically useful we must learn how to concentrate them in such a way as to obtain the maximum of effect from the machinery now available or from such additional machinery as we can afford.

In order to effect this concentration of effort we should seek out the main source or sources of human infection in childhood and direct our efforts to the control or elimination of these. They are not far to seek. The main source of childhood infection is the "open case"; the principal place of contamination is the infected home. The truth of this statement is proved by the observations of Opie and McPhedran, Krause, Asserson, Drolet and many others in America ; of Calmette, Bernard and Burnet in France; of Engel and Pirquet in Germany; of Lissant Cox, Midgely Turner, Dow and Lloyd, d'Arcy Hart and others in this country.

At this point let us consider for a moment the question of early childhood in relation to tuberculosis.

At this age-period the disease differs in several important respects from the tuberculosis of adults. The differences depend, to a great extent, upon the fact that, in early childhood the tissues and humours are, as yet, unaccustomed to encounter the tubercle bacillus. In later life, the human body, under favourable conditions, learns 
to adapt itself to a certain amount of tuberculous infection. In early childhood, this lesson is still to be learned or has only been partially acquired.

The tuberculosis of infancy and early childhood, then, is at first the tuberculosis of "virgin soil" and, as such, manifests itself in two distinct phases which are as follows:-

(I) A phase of primary localization in which the bacilli establish themselves at or near the portal of entry and in the nearest lymphatic glands. This phase I have ventured to call the "larval" phase. Pathologically it is represented by what Ghon and others have called the "primary complex." It is, as a rule, a stage of clinical latency in which the general health remains unaffected, and it usually escapes notice unless it happens to affect visible or palpable structures. Most of us pass through this stage without any subsequent ill-effects.

(2) A phase of early generalization, in which the infection spreads from its primary foci through the blood-stream and sets up secondary lesions elsewhere, often in important structures and organs.

The clinically recognized forms of childhood tuberculosis, upon which statistical records are based, belong, for the most part, to this "generalized" phase of the disease, and include, along with bone and joint tuberculosis, some of the most formidable manifestations of the disease such as tuberculous meningitis, early miliary tuberculosis, and caseous pneumonic phthisis.

If only we could arrest all cases, as nature arrests the majority, at the "larval " stage, we should have gone far to solve the problem of childhood tuberculosis.

"As nature arrests the majority"-what, it may be asked, is implied in that phrase ? Simply this; that, even in infected homes, the majority of the children, although infected, stop short of the "generalized" phase and escape without developing clinically obvious tuberculosis. This leads us to ask why it is that the others, a minority it is true, pass on into serious and often fatal forms of the disease.

There may be several factors at work; factors of individual resistance, accidental factors, nutritional factors. But there is at least one outstanding factor and that is the amount of infection to which the individual child is exposed. Everything points to the importance of this quantitative factor, the "amount" of infection. There is more clinical tuberculosis in the homes of cases with a "positive" sputum than in the homes of sputum-negative cases. There is more tuberculosis amongst the children of tuberculous mothers than amongst those whose father only is infected. There is more tuberculosis amongst the first-born than amongst the later children in infected families. The more intimate the contact, the greater the amount of the infection, and consequently the greater the risk of developing the disease.

From the point of view of prevention, the meaning of this is that we have two reasonable lines of action : (I) to diminish the amount of infection to which children in infected homes are exposed; (2) to raise the resistance of the children so that they may be able safely to tolerate exposure to such infection as they have to encounter.

In both these directions France has given and is giving interesting and valuable demonstrations.

Grancher devised and applied a method of diminishing exposure to infection by removing young children from tuberculous homes and placing them with healthy foster parents. In this way the constantly repeated re-infections which so often lead on to generalized disease were, in the great majority of cases, safely avoided. 
Calmette is, even now, engaged in his great experiment designed to raise the resistance of children by means of B.C.G. vaccine, so that they may be able safely to tolerate exposure to infection.

Neither of these methods, for which success is claimed in France, has so far been applied on any considerable scale in this country. Why? Perhaps part of the explanation lies in the fact that France's necessity is greater than ours. If we accept the figures furnished by Calmette himself; in France "more than 24 per cent. of the children born of tuberculous mothers or reared in an infected household" die of tuberculosis in the first year of life. Lissant Cox finds that $I^{\circ} 76$ per cent. of children so exposed succumb to tuberculosis in their first year. Dow and Lloyd find that $\mathrm{r} \cdot 88$ per cent. of the children of tuberculous mothers and $r .77$ per cent. of the children of tuberculous fathers die of tuberculosis in the age-group o-I year. It looks as if, for some reason or other, the infantile tuberculosis death-rate in infected homes in France is, or recently was, more than twelve times as great as in this country, and that up to the age of four years it is at least seven times as great [ $15^{\circ} 9$ in France to $\mathbf{2}^{\cdot 26}$ in Lancashire, Lissant Cox]. With this terrible child mortality, vouched for by French statisticians, it is not difficult to understand why special efforts have been made in France.

While France has devised the Grancher system for separating the child from the infected parents, we in England have done more, perhaps, than continental nations to separate infected parents from their children, by making a very large provision for adults of special hospitals and sanatoria supported by the State. And, even apart from our elaborate system of hospital and sanatorium segregation and treatment, theree are forces at work which are tending to solve our problem for us. Certain it is thato the mortality from tuberculosis in childhood has been falling rapidly from a time long. anterior to the recent developments in tuberculosis services. Dow and Lloyd, in their valuable paper emanating from the Research Department of the Brompton Hospital show that "during the past thirty years there has been a great fall in the mortality rates due to tuberculosis in this country," and that "this fall has been greater in children under the age of five years than at any other period of life." Doubtless this fall has been helped in recent years by the increased accommodation available for pulmonary cases since the Insurance Act of 19r2, but it was marked long before that date, showing that other causes had been at work.

Should we then be justified in leaving this problem to be gradually solved by the operation of natural laws? The fact that death from tuberculosis is from ten to twenty times as frequent in the offspring of tuberculous persons than in those of the same ages in the rest of the population is sufficient answer.

It is our duty, as a nation, to do all in our power to diminish this terrible toll of preventable disease. Nor is the tuberculosis death-rate in childhood a true indication of the extent of the problem. It appears certain that a more effective campaign to save children from the risks of home infection would have a favourable effect on the incidence of tuberculosis in adolescence and in young adult life. We are doing a great deal, spending a great deal, to accommodate and treat the cases that have developed recognizable tuberculosis, but not enough to prevent tuberculosis from developing.

We know that it is in the homes of open cases of tuberculosis that the risk is greatest and that the risk depends upon close and intimate contact with infected persons. Neither in France nor in this country has there been complete success in 
separating children from the infected parent or the latter from the children. In spite of the fact that Grancher in France proved the efficacy of his system, the "Euvre Grancher" remains an interesting demonstration only and has not been universally or even very widely applied in the country of its birth. And in spite of the expensive provision made in England and Wales for the hospitalization of adult cases, the separation thus effected is only temporary and there are thousands of homes to-day in which infants and young children are growing up in contact with the infection that is destined to keep our hospitals and sanatoria full in the next generation.

What are we to do about it? Vaccinate? Calmette's great experiment is taking place before our eyes. Basing his method on the opinion, for which there is much experimental support, that a "living" vaccine is that best calculated to produce adequate immunity against tuberculosis, and that this vaccine ought to be given in the first few weeks of life, he has already succeeded in having B.C.G. administered to over three hundred thousand children. The fact that the demands for the vaccine increase rather than diminish and that, apart from one regrettable incident where the precautions demanded by Calmette were not taken, there have been practically no suggestions of untoward results, suffices, in my opinion, to prove that B.C.G. vaccine, prepared according to the method used at the Pasteur Institute, may be given to infants without risk.

As to its value in preventing tuberculosis, future observation of the vaccinated children and of adequately observed "control" groups must supply the answer. In the meantime the results, though difficult to interpret from the statistical point of view, are promising and hold out hope for the future.

One thing is certain; that, if B.C.G. is to be used, it should be obtained from the Pasteur Institute, where its preparation is carried out on standard lines under the eye of Calmette himself, or else prepared according to the same technique in a special laboratory consecrated to this work only and from which all other strains of tubercle bacilli are rigidly excluded.

My personal view is that it is well worth trying, but I would limit its use to infants living in tuberculous homes. There is not, however, in this country, the terribly high infantile tuberculosis mortality which has doubtless been one of the main reasuns for the extended application of B.C.G. in France.

Lissant Cox has shown that the tuberculosis mortality amongst unvaccinated children living with tuberculous parents in Lancashire is actually less than that amongst B.C.G. vaccinated children of the same age living with tuberculous parents in France.

It has been my experience and that of my colleagues in Wales that it is. very difficult to find opportunities for the administration of B.C.G. Since 1928 we have only been able to give it to some fifteen infants-a proof that the conditions in this country are different from those in France.

But whether we decide to experiment with B.C.G. or with some other vaccine, we are faced with a problem which calls for further efforts in the direction of immunization. The infants born into tuberculous households are "virgin soil" to tuberculosis and therefore very susceptible to infection. So far we have failed to devise any widely applicable method to separate them from the risk to which they are exposed in their homes. In these circumstances the need for immunization within the first few weeks of life is obvious. It is possible that some "killed" vaccine may yet be proved to 
be effective for this purpose. Only by careful and continuous research can the best method be ascertained.

But apart from immunization which has not yet, in my opinion, advanced beyond the experimental stage, what ought we to be doing now ?

I confine my remarks to the pre-school age, before the School Medical Officer has come upon the scene; the age at which tuberculosis, when it appears in a form that is easily diagnosed, tends to assume such acute and fatal shapes. It is quite clear that, if anything is to be done, it must be done before obvious tuberculosis makes its appearance.

Can we by a careful study of the children in tuberculous homes pick out for our special attention those most likely to develop the disease? And if we are successful in doing so, can we save them from the danger of tuberculosis by placing them under specified conditions?

About five out of every hundred of such children are destined to develop tuberculosis in the pre-school period and others will do so later. Can we detect them and protect them before the blow falls? Frankly I do not know ; and I think it essential to find out.

The diagnostic means at our disposal are all of them laborious and all, perhaps, inadequate. They consist in repeated physical examinations and periodical weighing of "contact" children, and especially of X-ray examination at stated intervals, graded tuberculin tests, the examination of gastric contents for tubercle bacilli, and blood examinations. Seeing that children who have actually developed tuberculosis are often up to weight and in good general health, we cannot count on loss of weight or decline in health as indicators of impending "break-down."

M.cPhedran, a recognized authority, states that "no symptom complex has been found characteristic of tracheo-bronchial tuberculosis."

Even X-ray examination, though often of great utility, cannot be relied on to detect larval lesions in the non-calcified stage. Tuberculin tests, properly applied, offer a much more promising line for the detection of such cases, but only during the first year or two of life ; nor is the popular Von Pirquet test by any means adequate. Only serial tests with graded tuberculin dilutions carried out by the Mantoux technique of intracutaneous inoculation can be accepted as reliable, nor have we as yet sufficient knowledge to interpret their significance in all cases.

Rókay and, later, Von Csöke, have found evidence that the blood-sedimentation test often shows significant changes in child cases of tuberculosis of the lymphatic glands. This blood-test, and others such as the Von Bonsdorff test and the lymphocyte-monocyte ratio, may yet prove of considerable service.

The fact is that the detection of hidden activity in the larval tuberculosis of childhood has not yet been sufficiently studied and it is impossible to promise that, by this method or that, success is to be guaranteed. All we know at present is that one child out of every twenty in tuberculous homes is destined to get tuberculosis by the fifth year of life, and that we have no scheme to save him nor any plan to prevent others trom sickening and dying of tuberculosis during childhood and adolescence. Our Tuberculosis Schemes are all designed to be applied successfully once they get clinically evident tuberculosis-not before. To me this state of things is unsatisfactory. Here is, perhaps, the most important period of life in which to apply preventive measures-and we have no organized scheme to deal with it. 
The Tuberculosis Services, as at present constituted, have not sufficient staff to examine and test all the known contacts once, let alone investigate them thoroughly at intervals, during infancy and childhood. Nor have we, as yet, developed any adequate type of Institution into which "suspected" children could be admitted without branding them with the often erroneous diagnosis of tuberculosis. And yet it is at the stage when they are only "suspected" that we should deal with them. Once definitely diagnosed it is no longer correct to speak of "prevention," it is now a question of "treatment."

I think we want a new type of tuberculosis officer for this purpose and a new type of Institution, not instead of the efficient officers and the excellent Institutions that we already possess but in addition to them.

I should like to see "Child Contact Officers," preferably medical women, appointed to the staffs of some of our Dispensaries for the special investigation, observation, and "follow up" of the young children in tuberculous homes, and perhaps for their vaccination according to some approved method. I should like to see established, to receive the child cases "suspected" by these officers, a new type of Institution, with "crêche," "kindergarten," "summer camps" andi" hospital" sections; and fitted out with modern X-ray facilities.

It is hardly to be expected that Local Authorities should, as yet, undertake such a programme in addition to the heavy burden they already carry in connection with the segregation and treatment of tuberculosis.

But the organization of a Demonstration Unit on these lines would provide us with much needed information and would undoubtedly go far to guide us in. an important and almost unexplored field in tuberculosis prevention.

One thing is certain, that preventive effort, to be successful, must be concentrated upon the problem of infected homes.

\section{MAL-DESCENT OF THE TESTIS, AND SOME OF ITS PROBLEMS.}

\section{BY HAMILTON BAILEY, F.R.c.s.}

Surgeon, Royal Northern Hospital ; Consultant Surgeon, Essex County Council.

THERE are many problerns of interest connected with this subject, and I propose to discuss briefly some of them.

The Function of the Scrotum. - In man, at any rate, the testes fail to develup fully unless they are housed in the scrotum. If an imperfectly descended organ can be placed in the scrotum before puberty, or even shortly afterwards, providing there is no undue tension upon the cord and the blood supply is unimpaired that immature organ will develop. So long as it remains in the inguinal canal or the abdomen, development does not occur. The only explanation given for this arresting phenomenon is that the scrotum is a thermo-regulating mechanism. It is stated that for active spermatogenesis the testes must be kept at an even temperature, slightly below the normal body temperature, and that the scrotum, by virtue of its dartos muscle, provides a means of regulating temperature-for instance, when it is cold the dartos contracts and hugs the testes nearer the trunk. If man remained unclothed one could more readily accept this 